\title{
Adapting to Climate Change in Bangladesh: The Role of Social Capital
}

\author{
Dr. Syed Ashrafur Rahman ${ }^{1 *}$, Md. Amdadul Haque ${ }^{2}$ \\ ${ }^{I}$ Department of Political Studies, Shahjalal University of Science and Technology, Sylhet, Bangladesh, \\ Email:ashrafur-pss@sust.edu \\ ${ }^{2}$ Assistant Professor, Department of Political Studies, Shahjalal University of Science and Technology, Sylhet, \\ Bangladesh,E-mail:amdad-pss@sust.edu
}

*Corresponding Author: Dr. Syed Ashrafur Rahman, Department of Political Studies, Shahjalal University of Science and Technology, Sylhet, Bangladesh,Email:ashrafur-pss@sust.edu

\begin{abstract}
Climate change is now a serious threat of the world and Bangladesh is one of the highest vulnerable countries of this threat. Climate change adaptation is a crucial matter in Bangladesh. Because of repeated catastrophes, shortage of infrastructure, huge population thickness, more economic and social inequalities are growing the burden of the country in the tackling present changing situation. Social capital can plays an important role to adaptation of climate change challenges of the world. This paper analyzed the role of social capital to adapting the climate change challenges in Bangladesh. This study collected data from both primary and secondary sources.
\end{abstract}

Key Word: Climate Change Adaptation, Role of Social capital.

\section{INTRODUCTION}

Bangladesh is one of the extremely gamble countries, highest accessible to climate change because of her geographic position, socio-economic system and reliance on natural resources. Bangladesh, a lower middle income, lowland country include over 230 rivers and 164,107,433 million people (Bangladesh Population 2020), per capita Gross Domestic Product (GDP) of almost \$ 2064 dollar (Dhaka Tribune, 11 August,2020), is familiar around the world one of the top tier of disaster affected countries and in danger to impacts of global heating and the climate change. Bangladesh is located in South Asia, connected to India on the west, north and east, to Myanmar in the south-east, and near the Bay of Bengal. The whole country is 147,570 sq.km comprised of mainly of low land (about 80 percent) have left maximum of the country vulnerable to flooding throughout the rainy season. A link of rivers of the eastern Himalayas, get hold sediments ahead their roads constitute a huge region of the territory in the basin. The weather of Bangladesh can mainly feature by intense heat, flash flood and very damp weather and trio seasons- the summer season, the rainy season and the winter season (The Daily Star, March 4, 2019). As stated in 'Global climate risk index 2019, Bangladesh position seventh between the countries, severely damaged by outmost climate effects in 20 years since 1998. Only in 2018, 407 peoples died in Bangladesh because of highly climate relevant effects- flood, landslide, storms and cyclone. Rajnagar Upazila one of the highly climate vulnerable Upazila in Moulvi Bazar district. It has eight unions. Among the eight unions, Kamarchak union was severely affected by flash flood in 2017. More than 20,000 peoples of the Kamarchak union were directly affected by this flash flood. Hundreds of families took refuge in unused buildings, schools or moved to their relative houses after their villages were inundated of this flood.

Social capital is an imperative tool that may help policymakers to implement more comprehensive and cohesive approach in adapting to climate change impacts. The adaptation process of the Kamarchak Union of Rajnagar Upazila, Moulvi Bazar in the light of social capital is an aptly timed study to measure the effect of how the social capital can help to facilitate the suffering communities of flood and other climatic disasters.

\subsection{Objectives}

This study provided an abstract framework upon which one can determine how social capital can ease the transition of climate adaptation that societies faces. The main objectives were- 
a. To analyze attributes of social capital in communities to adapt with climate issues.

b. To identified the link between social capital and climate risk adaptation.

\section{METHODOLOGY}

This study have been followed both qualitative and quantitative approaches. Data has been collected from both primary and secondary sources. Simple random sampling of survey methods has been used to collect data. Sample size was 55. Among the respondents 53 were mass people and 2 were officials of Water Development Board of Moulvibazar District. The quantitative data processed through editing to improve their quality and coding to convert them to the form of numerical codes representing attribute of variables. The study used Statistical Package for Social Science (SPSS) software to get appropriate combination of data. For bi-variety analysis of the data, different tools of inference employed such as the correlation, t-test, and chi-square test to find the relationship among the variables regarding the objective of the research.

\subsection{Social Capital}

The term 'Social capital' came from the field of sociology and political science and initially came in to sight in Hanifan (1916) study of rural Schools community centers in the United States. The term Social Capital defines the different sources that people might have between their connections in families, societies and other social networks. Social capital link people together and support them creating networks as well as their near associate and next door neighbors.

Social capital can call a "Social plaster," which holds people along with in families and societies and provide them a feeling of belonging in an increasingly divided and uncertain planet. Social capital is allowed assist in bonding people all-organized and developing a felling of common identification, in bridging societies to the broader world through connection which enlarge their societies with others, and in networking people to favorable circumstances and framework of support.

Social capital can be simply classified in a number of ways- as bonding social capital, bridging social capital and linking social capital (Woolcock, 2001). Bonding social capital, define by 'heavy efforts'; thick link framework and heavy, but regional belief like connection with family members; friends and next door neighbors; sharing same inhabited future. Bonding social capital mentions to the connections among of the same minded people, either the pillar of uniformity (Schuller, Baron, \& Field, 2000). Bonding social capital point out the link among people in the same circumstances. It may be their nearest by resident, friends or alike household (Woolcock 2001: 13-4). Bonding social capital formed on locality. The connections can assist to supply social help by admitting people to access help, knowledge, and sentimental support. Bonding social capital may confirm a practical social task by supporting a crucial source of help to people who deteriorate from socio-economic deprivation either weak physical fitness.

Bridging social capital defined by 'soft efforts'; limited thick, but additional inter-sect efforts between people from several ethnic; terrestrial; and professional history, but with same financial position and political power like connections with local leaders. Bridging social capital covers up far connections of those men, like as colleague and close friends (Woolcock 2001: 13-4). Bridging social capital outline social connections of interchange, frequent of alliance among people include mutual profits of objectives but different social integrity (Pelling and High 2005). The advantages of bridging social capital are wide-ranging and can expand capacity to get message, ability to get to entry to dominance either well position among the network, either capacity to bigger acknowledge additional favorable circumstances (Adler and Kwon 2002). Bridging social capital extending connections can create useable the assets and favorable circumstances that continue in one network to a unit of other (Stone and Hughes 2002).

Linking social capital defined by soft bonds of threats and amity like, connection with the people who have too political and financial power, performing through institutional bureaucratic framework, like government officials but they are not local people. Linking social capital, that connect different people in different circumstances, like those who are completely exterior of the society, so allowing part of a group to connect a broad of assets apart from are obtainable in the society (Woodcock 2001: 13-4).

Linking social capital includes social links among those in power which may be served to obtain wealth or power (Stone and Hughes 2002). Linking social capital is obviously at the heart to welfare, 
particularly in third world countries and societies. Investigation has been showed that unless linking kinds of social capital might not be educate for social progress to appear (Flora 1998).

Putnam stated that few model of social capital are extremely official, like a PTA (Parent-Teacher Association organization). Some types of social capital are unofficial, like the groups of people who get together at the sports club weekend morning. Few types of social capital are thickly interweaved, like a faction of people who work jointly every day at the departmental store and go to bar at the weekend. One more hidden social capital that is too narrow, like people virtually join at the supermall, when held up in line.

Maximum sociologists outline social capital as assets create accessible through social connection (Kadushin, 2012). The prime objective of this study is how social capital can help the people to adapting climate change challenges in Bangladesh.

\subsection{Climate Change Challenges in Bangladesh}

Bangladesh has an exclusive geography, located only the Bay of Bengal and setup one of the wide ranging basin in the earth along a close connection of branches of the Ganges, Brahmaputra and Meghna (GBM) waterways(Climate Change Profile: Bangladesh, April, 2018). Around a year, vast areas of Bangladesh hurt from severe climate change effects such as cyclones, floods and erosion. Those negative effects are decreasing the growth of the country and breakdown socio-economic and environmental order (Bangladesh population 2018). Most of its population are afflicted by those catastrophes, they are by this time serving instruments through those, giving too attempt include in hard cash in their seeking of development and through confronted different social restrictions (UNDP 2008). As stated to the Climate Change risk index of 2015, Bangladesh's economy is at risk to climate change than any other country too. Because by climate change in Bangladesh above the 40 years were at an predicted $\$ 12$ billion dollar decreasing annually at 0.5 to 1 percent and expected loss of DGP 6.7 percent or $\$ 171$ billion by 2050 (The Daily Star, September 27, 2019).

In addition, there is growing migration tendency in Bangladesh include increase in domestic migration and a quickly increasing city population are to a remarkably increase the outcome of climatic pressure and disturbances (Martian etal.2013). Due to climate change-effect pressures like frequent severe climate effects, increasing sea level, land salinity and flooding a lot of peoples have been forced to migrate out of their societies .That raise rural to urban migration has create serious stress on urban food and water system. Bangladesh is effect by a drastic cyclone one almost every three years. According to UNDP report, Bangladesh position first of all countries in the earth in terms of effects of tropical cyclone, due to topography and climate change (MoEF 2009). As well as, Bangladesh is in danger to flooding, about $80 \%$ of its cultivating agricultural land affected by flood. Flood arises from rainfall in the total of the Ganges, the Brahmaputra and the Meghan (GBM) valley (World Bank 2010). Each year flood appeared in July and August. In an almost a year, approximately $25 \%$ of the country is effected by flood. Almost every 4-5 year, severe flood occurring in the country and $60 \%$ area of the country affected by flood .This floods has destructive impact river Bank erosion, which effect in the casualty of thousands of hectares of cultivating agricultural land (MoEF 2009). In addition, floods increase to salinity of coastal lands, causing loss of agriculture and productive agricultural land. Approximately 1.2 million hectares of agricultural land are by this time affected by deferent levels of land salinities (World Bank 2011). Several climate change research identified twelve complex and reinforcing impacts of climate change on Bangladesh. These are: 1. Sea level rise; 2. Cyclone (intensity and frequency); 3. Deeper penetration of saline water; 4. Erratic rainfall; 5. Flood (intensity and frequency); 6. Drought; 7. River bank erosion; 8. Health security; 9. Food security; 10.Water security; 11. Land slide in Chittagong Hill Tracts; and 12. Migration (Rahman, 2017).

Inevitable climate change prediction for Bangladesh are a fewer uncertain than for other countries. There is a consensus including highest standard both hotness are predicted to rise by 1.8 degree Celsius by the 2060s and 2.7 degree Celsius by the 2090, despite of few prediction recommend increase up it 4.1 degree Celsius for the 2090s (Compared for the 1970-2000 mean). Comparatively sea level rising in Bangladesh is highest than more other countries, because of this occurring flash flood of low coastal areas. This will affect huge number of people by 2050 around 27 million peoples will be at danger (Climate change profile 2018). 
Flash floods one of the common climate change threats in northeastern part of Bangladesh because of surrounding hill areas. During huge rain drops follow in the Assam and Meghalaya hill region of India, flood water rapidly come towards haor region of Bangladesh by way of the cross broader rivers.

On April 2017 flash flood, drastically destroyed almost 220000 hectors of agricultural land and damage about 850000 household, severely damage to food crops, housing and infrastructure, with bridge, culvert and roads. In addition, more than 20 million people were facing severe food deficit this year (2017-2018). The severely flash flood damaged districts were Sylhet, Moulvi Bazar, Habiganj, Netrokona and Kishoreganj.

In Moulvibazar district, flash flood affected Upozilas are 07, Unions 60, households 74,594, fully damage agricultural land 9.914 hectors, fully damage houses 194 and partially damage houses 284 (DDM Report May 1, 2017). In Rajnagar Upazila, 50 villages were flooded in two Unions after the dyke on the Monu River was breached at four points of flash flood in 2017. It destroyed 850 hectares of paddy and partially damaged crops in over 1,100 hectares (Saiful Islam, April 26, 2017)

Among the eight Unions of the Rajnagar Upazila, the Kamarchak Union was severely affected by 2017's flash floods, due to damage of flood control embankment of Monu River. At least 30,000 villagers were marooned by flood of Kamarchak and Tengra unions. More than 20,000 peoples of the Kamarchak union were directly affected by this flash flood. Hundreds of families took refuge in unused buildings, schools or moved to their relatives houses after their villages were inundated of this flood (ANI 06 June, 2017).

\subsection{Role of Social Capital in Climate Change Risk Adaptation in Bangladesh}

Climate change adaptation takes a key part in promoting the development of a country. The IPCC outlines adaptation as the, " accustoming inherent or human order in reaction to real or predicted climatic provocation or their impacts that balances suffering either avail advantageous of favorable circumstances" (IPCC,2012). Climate change adaptation and disaster threats decline appear to be two separate grounds but nevertheless both are same in their goal that is to made elasticity in the faces of challenges of risk. The connection among the two areas in one inquiry is described as, "climate change adaptation needs the refurbishing and remodeling of development, social and economic implementation to address efficiently advanced or predicted environmental alteration" (Venton, P and La Trobe, S.2008).

Social capital plays an important role throughout the time of catastrophe and climate change impacts like these created by whether change in Bangladesh. Naturally, many extreme impacts of manmade worldwide heat to yet has originated serious climatic impacts, increased drought desert, and consistently flooding threats along coastal region such as long time flood and severe cyclone in Bangladesh (IPCC,2012). In this perspective social capital can help Bangladeshi peoples to adapt weather relevant catastrophe and promote reformation and permanent adaptation. Social capital can encourage peoples to protecting flooded or catastrophic region and to insistence political leaders for cooperation in managing climate changes related challenges (Aldrich, 2010).

Bonding social capital, a main component of social capital, is an significant resource in weather change-relevant catastrophe frame work (IPCC,2014:27). Throughout the time the environmental threats households and near chains assist the progress of physical, sentimental and economic help. Behind help and information, bonding social capital can actively influence decisions to leave or stay in climate change affected areas, and household members first time hesitating to go away from a climate change affected area may be convince by the family or associates to leave. The deep social connection can assist to quickest steps after catastrophe and giving assistant.

In addition, bridging social capital is very significant for supporting people keep the impact of catastrophe. Social capital plays as a public assets in helping while societies during sever effects.

Linking social capital is connecting people to help decision making, and permit contact to other communities support to accelerate political change. In predicted climate change threats, connection between a local society and central governmental officers can support contact to resources accelerate weather change disaster improving.

All three types of social capital expand people abilities to help during the time of a climate change threats. In the example of climate change disaster, bonding social capital can do outstanding matter of 
quickest help. In the long run, bridging and linking social capital support for financial development and making favorable circumstances.

In this situation, there is increasing acceptance of the important role of social capital through steps to the different climate change challenges and short and long time.

\section{FIELd Survey Data ANALYSIS}

\subsection{General Respondents}

General respondents are primarily consists of farmers. But there are other factions such as teachers, lawyers and people of other professions. The respondents were chosen at random basis with no prior condition other than that they are permanent residence of the studied area.

\subsection{Social Media User}

Out of 53 general respondents, $41.51 \%$ uses social media. It is indicate that a significant number of the people does not reap benefit from the social media. Also this is a passive indication that the passive bridging and linking bond between the respondent and the respected sources (i.e. social groups, local government institutions) are weak.

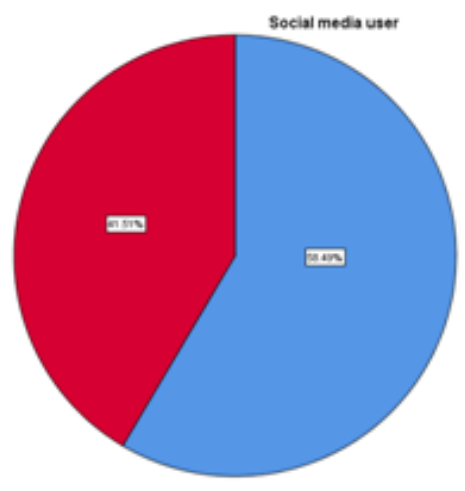

Fin

\subsection{Help from Union Paris Had}

Regarding the question is to whether they get help from the Union Paris had or not after the climate change disaster, majority of respondents, $54.72 \%$ (29 respondents) answered in the negative. This is not only an indication of low level of linking capital, but also shows a lack of non-compliancy of the people to the local authorities.

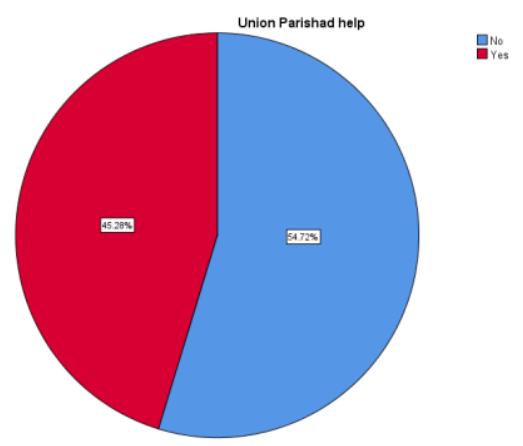

However, upon being asked about the activities of the UP, the UP Chairman replied that hundreds of people had been provided sufficient relief by UP but he could not provide any more details.

\subsection{Access to Shelter House}

Access to shelter house during climate change disaster is considered as one of the key variables regarding the problems of climate change adaptation. Asking the question, whether they have access to shelter house, majority of the respondents replied in the negative. 


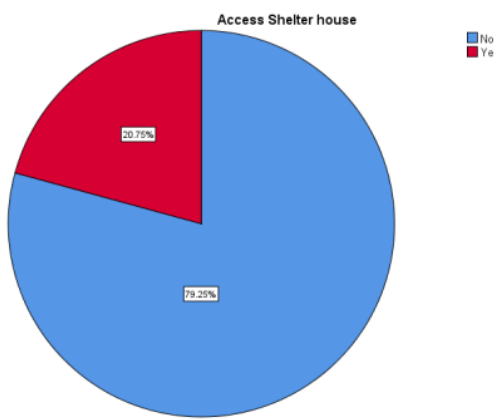

Among the 53 respondents, only $20.75 \%$ or 11 of them answered in the positive, others stated that they did not have any access to the shelter house during the climate change disaster of their locality.

The idea of shelter house, however, has mixed perception among the respondents. Some do not like to consider the local primary school as their shelter house in times of disaster.

Responding to this question, the respondents also replied in the affirmative that they consider the logistical support from their kin as the primary source of shelter in the times of disaster. So, we see during the disaster time bonding social capital plays an important role.

\subsection{Farmer's Group}

Participating in a farmer's group is also considered as one of the key indicator of social capital in climate adaptation.

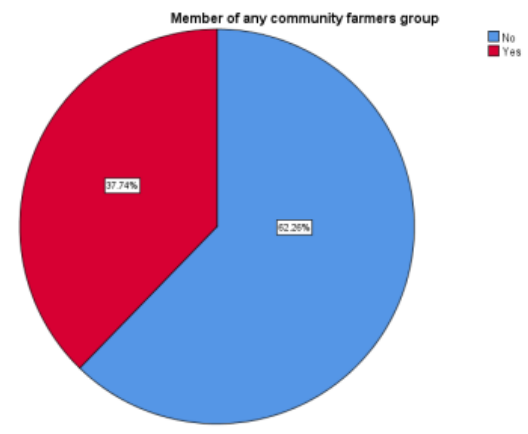

Out of 53 respondents, only $3.77 \%$ that means only 2 of them answered in the positive. This is shows the lack of community development among farmers in the study area. So we see bridging social capital role are limited in the study area.

\subsection{Climate Adaptive Seeds and Fertilizers}

Out of the 53 respondents, only $11.32 \%$ said that they received climate adaptive seeds and fertilizers. As the data collectors observed, most of the respondents do not have any clear idea about the climate adaptive seeds or fertilizers and their implications. It is not only shows a poor role of linking social capital but also highlights the institutional weakness of the governing bodies at the local level.

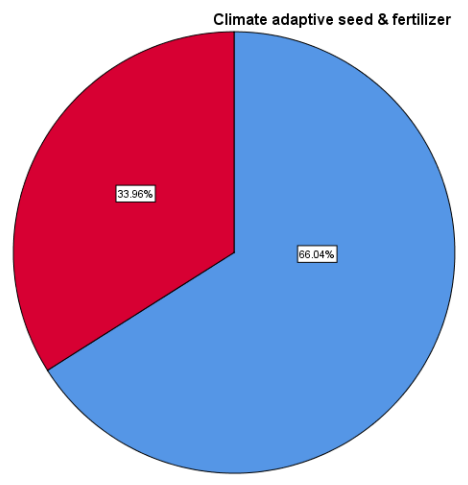

Пํos

\subsection{Expatriates' Help Through Social Media}

Financial help from the expatriates plays a vital role in the disaster prone community especially in the development of the adaptive measures. 


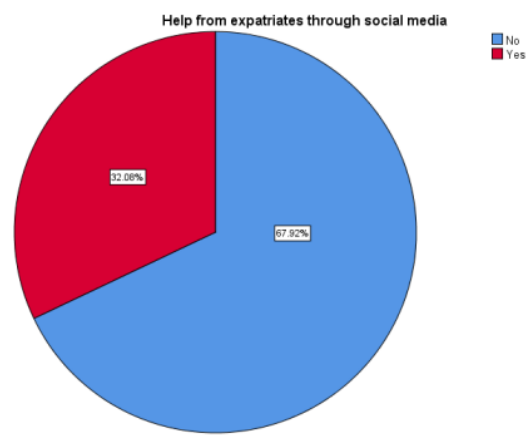

However, less than $50 \%(32.08 \%)$ respondents have answered that they received financial support through using social media platforms from the expatriates of their community. This number is significantly low.

And also if we measure social capital in relation with climate adaptive seed and fertilizer and farmers' group activities, we find the following crosstabs analysis-

Member of any community farmers' group * Climate adaptive seed \& fertilizer Cross tabulation

\begin{tabular}{|c|c|c|c|}
\hline \multicolumn{4}{|l|}{ Count } \\
\hline & \multicolumn{2}{|c|}{ Climate adaptive seed $\&$ fertilizer } & \multirow[b]{2}{*}{ Total } \\
\hline & No & Yes & \\
\hline Member of any community farmers No & 27 & 6 & 33 \\
\hline \begin{tabular}{|l|l} 
group & Yes \\
\end{tabular} & 8 & 12 & 20 \\
\hline Total & 35 & 18 & 53 \\
\hline
\end{tabular}

\begin{tabular}{|c|c|c|c|c|c|c|c|}
\hline \multicolumn{8}{|l|}{ Chi-Square Tests } \\
\hline & Value & df & $\begin{array}{l}\text { Asymptotic } \\
\text { Significance } \\
\text { sided) }\end{array}$ & $\begin{array}{l}\left(2-\mid \begin{array}{l}\text { Exact } \\
\text { sided })\end{array}\right) \\
\text { side }\end{array}$ & Sig. & $\left(2-\mid \begin{array}{l}\text { Exact } \\
\text { sided })\end{array}\right.$ & Sig. (1- \\
\hline Pearson Chi-Square & $9.710^{\mathrm{a}}$ & 1 & .002 & & & & \\
\hline Continuity Correction $^{b}$ & 7.935 & 1 & .005 & & & & \\
\hline Likelihood Ratio & 9.710 & 1 & .002 & & & & \\
\hline Fisher's Exact Test & & & & .003 & & .002 & \\
\hline Linear-by-Linear Association & 9.527 & 1 & .002 & & & & \\
\hline $\mathrm{N}$ of Valid Cases & 53 & & & & & & \\
\hline
\end{tabular}

\subsection{Official Respondents}

A general meeting with the Water Development Board (WDB) officials, of the district WDB office, primarily charged by the executive engineer.

\section{Main problems regarding flood management and River Training in Moulvibazar district.}

The river Manu is originated from the hilly areas of Tripura, India. Naturally, 91\% catchment area of the Manu River is in India. For that reason, if the areas of Manu river which is situated in India catches even less amount of rain water than Moulvibazar, all the rain water is being dumped and flowed in the Moulvibazar district. This unfortunate situation overflows the river beyond its capacity which ultimately causes of flooding. In addition, there is no communication line between the barrage in India, which exhausts water from time to time without any prior knowledge of the WDB officials and catches the flood preventive apparatus off-guard.

Regarding the River Training program of Manu River in Moulvi Bazar, there are two problems that are identified. These are:

1. There are problems regarding land acquisition and relocation of already existed structures (i.e. mosque, schools, hospitals etc).

2. There are various problems that officials have face regarding dredging materials and overall management. For example, the WDB officials have identified that the dredging materials are too costly and cumbersome for the local authority to manage. Therefore, they have to wait for a larger 
and more national level projects to get their share of dredging materials. This delays the dredging of the river Manu, which in-turns creates havoc in the flood management system.

\section{WDB AND ITS SOCIAL ASPECT}

\subsection{WDB Have Identified 5 Major Awareness Aspects that They Perform. These Are}

1. The web and app based flood alert system.

2. Flood alerting through local officials.

3. Flood alert through local administrators.

4. Communities reach through local constituent representatives.

5. Social activities through social media platforms and other electronic and print media.

6. Through mobile-based alert service.

7. Appointing 'Tathya Odhikar Kormokorta' or Information Officer to maintain flow of information to the public.

8. Putting up relevant banners and sign boards to aware people regarding river canal preservation.

Regarding their social awareness program, the officials have kindly notified that there are some limitations and grounds to improve from their part. They have aptly noted that, general people are not widely informed about the services that government agencies provide them which are causes to be deprived of many governmental services.

\subsection{Other Observations}

Through filed visits, there are other observations that are important to be noted in the report.

First of all, people are, in the studied area, not capable to grasp the notion of adaptation in the changing climate. It is imperative for the NGOs and government initiative to educate people about the climate change adaptation.

\section{FINDINGS AND RECOMMENDATIONS}

1. Linking and bridging social capital metrics are very poor especially in the farmers' community. It has to be improved to gain a more asymmetrical nature of the modern social capital.

2. People do not necessarily to get their desired level of support from the Union Parishad as the data suggests that more than half of the respondents do not recall receiving any help from the Union Parishad. This may also suggests that the linking aspect of the social capital in the study area is also very weak. In addition, empirical observation suggests that, there is a communication gap between the general people and the Union Parishad. The Union Parishad should be more cohesive in their activities.

3. Most of the people in the study area do not consider the UP as their primary source of resort during the times of calamities. Almost $100 \%$ of them suggest that they primarily rely on Family and Friends (Bonding Social Capital) in times of disaster. Although this may be a biased outcome because of the demographic characteristics of the study area, but people's reluctant to view other networks such as Bridging (ie. Comradeship), and Linking (ie. constituent representatives), as even a resourceful alternative, so study shows that the social capital of the study area primarily consists of Bonding social capital. The apparatus of local government cannot function to its full extent.

4. In investigating the state of social capital, we also show the fact that among the sampled population only about $3 \%$ of them have told that they are members of any farmers' group. This remarkable statistical fragment is not an anomaly, but a fitting trend that has engulfed the farmers' throughout the country. The lack of community mobilization among farmers in the study area will have a significant negative impact on their livelihood in the context of climate change adaptation. In addition, whether it is lack of community development or organizing capacity or not, the low level of linking social capital certainly harming them in educating themselves regarding climate adaptive fertilizers and seeds. 
5. It is imperative to note that almost all the respondents disdain WDB and its activities either because of their ignorance of its activities or the WDB is not performing in a socially cohesive way which would definitely ensure a much larger percentage of awareness among public and also educate them about their rights and the facilities which they are entitled as a citizen.

6. Social capital is undoubtedly a proven metric in the scenario of climate adaptation. But, in the case of the studied area, the destitution of socio-economic condition acts as obstacles for the social networking to foster. However, through this study, we have found that the social networking (social capital, media) have a great rooms to play to aid the vulnerable communities. For example, if people had a more strong social networking apparatus, they would have reaped the benefits of extracting many resources and increase their awareness regarding many aces that an active social network may offer.

7. It has been observed through field visits that the marginalize people do not have sufficient means to levy any additional resources other than their kin and comrades. This lack of ability however, paints a more symmetrical picture of social networking where only bonding is preferred. There has to be a governmental intervention in this matter. The asymmetrical nature of the social capital is the foundation of a proper adaptation in the context of climate change. The government should take adequate approach in rebuilding social trusts and ensure proper access to its services in the marginalized community.

\section{REFERENCES}

[1] Aldrich.D.P.2010. "Social Capital in Post-crises resilience." Journal of Homeland Security, 6.1-10

[2] ANI, 06 June 2017

[3] Bangladesh Population 2018.World Population review.com

[4] Climate Change Profile: Bangladesh. April 2018. Ministry of Foreign Affairs of the Netherlands

[5] Coleman, J.S.1994. "Social Capital, human capital and investment in youth." In A.C. Petersen and J.T.Mortimer (Eds.), Youth Unemployment and Society.p.34-50.Cambridge University Press.

[6] DDM Report, 1 May 2017

[7] Flora, Jan L.1998. "Social Capital and Communities of Place," Rural Sociology 63(4):481-506.

[8] Hanifan, L. J. 1920. Social capital its development and use the community. Chicago: Silver, Burdett.

[9] Healy, Tom.2002. Social Capital: The Challenge of International Measurement-Paper .The Measurement of Social Capital at International Level. Paris.

[10] IPCC, 2012

[11] IPCC, 2014

[12] Kadushin, C. (2012). Understanding social networks : theories, concepts, and findings. Oxford University Press.

[13] MoEF(2009). Bangladesh Climate change Strategy and Adaptation plan. Ministry of Environment and Forests, Government of the People's Republic of Bangladesh.

[14] NIRAPAD, 2018

[15] Pelling, Mark and Chris High. 2005. "Understanding Adaptation: What can Social Capital Offer Assessments of Adaptive Capacity?" Global Environmental Change15 (4):308-19.

[16] Putnam, Robert D.2000.Bowling Alone: The Collapse and Revival of American Community. New York: Slimon and Schuster.

[17] Stone Wendy and Jody Hughes. 2002. Social Capital: Empirical Meaning and Measurement Validity. Australian Institute of Family Studies.

[18] Rahman, A. (2017). SDGs and Climate Resilience Development. The Daily Star, 27th February.

[19] Schuller T. Baron, S. Field, J.2000. "Social Capital: A review, and critique.” In Baron et al.(Eds.), Social Capital: Critical Perspectives: Oxford University Press.

[20] Szreter S. and Michael Woodcock. 2004. "Health by Association, Social Capital, Social theory and the Political Economy of Public Health," International Journal of Epidemiology33 (4):650-67.

[21] The Daily Star, 26 April 2017

[22] The Daily Star, March 4, 2019

[23] The Daily Star, 27 September, 2019 
[24] UNDP (2008): Climate change and the vulnerability of Bangladesh, Published climate cell, Department of Environment, Comprehensive Disaster Management Program, Dhaka.

[25] Venton, P and La Trobe, S.2008.Linking climate adaptation and disaster risk reduction. Tear fund, Teddington.

[26] Widen-Wolff, Gorilla et al.2008. "Information Behavior Meets Social Capital: A Conceptual Model." Journal of Information Science 34(3):346-55.

[27] Woodcock, M. 2001. "The place of Social Capital in understanding: Social and Economic outcome." Canadian Journal of Policy Research, 2 (1), 11-17.

[28] Woodcock, M. and Narayan, D.2000. "Social capital: Implications for development theory, research, and policy." World Bank Observer, 15(2), 225-249.

[29] Woolcock, M. (2001). The Place of Social Capital in Understanding Social and Economic Outcome. Canadian Journal of Policy Research, 2(1), 11-17.

[30] World Bank 2010. "Economic Adaptation on Climate Change in Bangladesh,” World Bank report-2011

Citation: Dr. Syed Ashrafur Rahman, Md. Amdadul Haque. "Adapting to Climate Change in Bangladesh: The Role of Social Capital" International Journal of Humanities Social Sciences and Education (IJHSSE), vol 7, no. 10, 2020, pp. 137-146. doi: https://doi.org/10.20431/2349-0381.0710017.

Copyright: (C) 2020 Authors. This is an open-access article distributed under the terms of the Creative Commons Attribution License, which permits unrestricted use, distribution, and reproduction in any medium, provided the original author and source are credited. 